\title{
Reliability of cuff pressure gauges
}

\author{
Julien Raft ${ }^{1,2}$ - Anne-Sophie Lamotte ${ }^{2} \cdot$ Bruno Maury $^{3} \cdot$ Isabelle Clerc-Urmès ${ }^{4} \cdot$ Cédric Baumann $^{4}$. \\ Philippe Richebé ${ }^{*} \cdot$ Hervé Bouaziz ${ }^{5}$
}

Received: 4 May 2018 / Accepted: 25 July 2018 / Published online: 30 July 2018

(c) Springer Nature B.V. 2018

\begin{abstract}
Cuff pressure gauges are the only recommended instrument to perform controls on endotracheal tube cuff pressure during anesthesia. No calibration is mandatory for these devices. The aim of this study was to describe the level of conformity of various cuff pressure gauges. The single-center measurements were performed with a cuff pressure calibrator on all cuff pressure gauges that were usually used in the operating room. Seven measurements (repeat three times) on each cuff pressure gauges at different levels of pressures (i.e. $0,10,20,27,30,40$ and $50 \mathrm{cmH}_{2} \mathrm{O}$ ) were performed. Our homologation criteria were either the reliability of the leak test (value of cuff pressure gauges maintained at $120 \mathrm{cmH}_{2} \mathrm{O}$ during $5 \mathrm{~s}$ ) or the difference between the values of the cuff pressure tested and the calibrator below $1.3 \mathrm{cmH}_{2} \mathrm{O}$ at the range of $20-30 \mathrm{cmH}_{2} \mathrm{O}$. A total of 567 measurements on 27 cuff pressure gauges were performed. Only $30 \%(n=8 / 27)$ of the cuff pressure gauges reach our homologation criteria. 30\% $(n=8 / 27)$ failed at the leak test. $48 \%(n=13 / 27)$ of the cuff pressure gauges tested, had a calibration variation error $>1.3 \mathrm{cmH}_{2} \mathrm{O}$ on the levels of pressure between 20 and $30 \mathrm{cmH}_{2} \mathrm{O}$. A minority of cuff pressure gauges went through our homologation criteria. These results demonstrate us that there is a real problem of the reliability and the follow-up of those medical devices. This study suggests to reinforce biomedical engineering control on these devices.
\end{abstract}

Keywords Calibrator $\cdot$ Manometry $\cdot$ Reliability $\cdot$ Validity

\section{Introduction}

Tracheal intubation constitutes a routine part of anaesthetic practice both in the operating room as well as in the care of critically ill patients. Inaccurately size endotracheal tubes cuff may lead to inadequate ventilation during anesthesia [1]. Lower cuff pressure does not protect the trachea from leakage of gas or secretions passing around the cuff. Isolation of the lower part of the airway enables efficient lung ventilation and reduces the risk of ventilation associated pneumonia [1]. With the new generation of ventilators, it is now easy to detect a leak of the endotracheal tube cuff and to correct it with some insufflation of the cuff. Besides the detection of a leak, monitoring cuff pressure is a well-proven

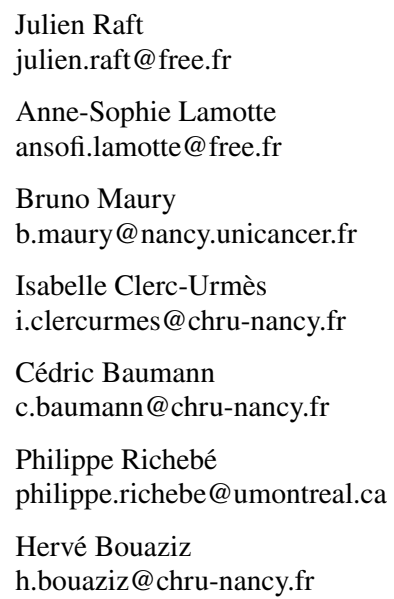

Department of Anesthesiology and Pain Medicine, University of Montréal, Maisonneuve-Rosemont Hospital, 5415 Boulevard de l'Assomption, Montreal, QC H1T 2M4, Canada

2 Department of Anesthesiology, Cancer Institut of Lorraine Alexis Vautrin, University of Lorraine, 6, Avenue de Bourgogne, 54511 Vandoeuvre-lès-Nancy, France

3 Biomedical Engineering, Cancer Institut of Lorraine Alexis Vautrin, University of Lorraine, 6, Avenue de Bourgogne, 54511 Vandoeuvre-lès-Nancy, France

4 Clinical Research Support Facility PARC, UMDS, University Hospital of Nancy, Vandoeuvre-lès-Nancy, France

5 Department of Anesthesiology and Intensive Care, University Hospital of Nancy, 29, Avenue du Maréchal-de-Lattre-de-Tassigny, 54035 Nancy Cedex, France 
technique to prevent ventilator associated pneumonia as it decreases the risk of aspiration of respiratory secretions from the supraglottic space. But there is a morbidity associated with endotracheal tube cuff over-inflation. Excessive cuff pressures above $30 \mathrm{cmH}_{2} \mathrm{O}$ decrease mucosal blood flow, with near complete stop of flow around $50 \mathrm{cmH}_{2} \mathrm{O}$ [2]. Tissue ischemia may occur beyond an endotracheal tube cuff pressure of $30 \mathrm{cmH}_{2} \mathrm{O}$ during a period of more than $15 \mathrm{~min}$ [3-5]. These may impair tracheal mucosal perfusion and cause tracheal damage like mucosal ulceration, sore throat, hoarseness and dysphagia [6]. To prevent those damages, it is necessary to adjust endotracheal tube cuff pressure [7]. Endotracheal tube cuff pressure monitoring is still one of the standard of care offered to anesthetized patients in the operative theater. A cuff pressure gauge is the only recommended instrument to perform these controls. Although, no calibration is mandatory on these devices.

The aim of this study is to describe the level of conformity of various cuff pressure gauges used daily in the operating room and thus to test for their reliability.

\section{Methods}

To test cuff pressure gauges, we used portable, round pressure gauge new calibrator 700G02 (Fluke ${ }^{\mathrm{TM}}$, Eindhoven, Netherlands) for fast and accurate calibration test results. This pressure gauge calibrator had an accuracy to $0.04 \%$ of reading. The calibration uses measurement standards traceable to the National Institute of Standards and Technology (NIST, Gaithersburg, USA). The calibrator had a direct connection to the cuff pressure gauges without the necessity to use an endotracheal tube cuff. No patient was necessary. It is not a clinical study but an experimental study on devices.

Before starting the measurement of each cuff pressure gauges, temperature and hygrometry were collected with a digital probe NUM TH METAL reference 10948 (JRI, Fesches-le-Châtel, France). The uncertainty of temperature was $0.5{ }^{\circ} \mathrm{C}$. The uncertainty of the hygrometry was $1.2 \%$. All data were collected with a Spy RF® N temperature recorder modele N2 reference 06429 (JRI, Fesches-le-Châtel, France).

The first way to test the cuff pressure gauges was to performed a leak test. This leak test was performed for each cuff pressure gauges by applying a pressure of $120 \mathrm{cmH}_{2} \mathrm{O}$ and closing its outlet for $5 \mathrm{~s}$. If the pressure was falling down during the following $5 \mathrm{~s}$ of observation, the test was considered as a failure. Then, seven measurements on each cuff pressure gauges at different pressures were made at: $0,10,20,27,30,40$ and $50 \mathrm{cmH}_{2} \mathrm{O}$ were performed. All these measurements were repeated three times for each cuff pressure.
As said above tissue ischemia may occur beyond a endotracheal tube cuff pressure of $30 \mathrm{cmH}_{2} \mathrm{O}$ during a period of more than 15 min [3-5]. Nevertheless, to use inaccurate size of endotracheal tubes cuff may lead to inadequate ventilation during anesthesia. So, for this study, the optimal pressure to avoid complications was first set at $27 \mathrm{cmH}_{2} \mathrm{O}$ which explains why each cuff pressure gauges were tested at the pressure of $27 \mathrm{cmH}_{2} \mathrm{O}$ in regards to the French guidelines [8].

Our homologation criteria were: either absence of failure to the leak test (value of cuff pressure gauges does not move at the pressure of $120 \mathrm{cmH}_{2} \mathrm{O}$ and for $5 \mathrm{~s}$ ) or the difference between the values of the cuff pressure tested and the calibrator below $1.3 \mathrm{cmH}_{2} \mathrm{O}$ at the range 20 and $30 \mathrm{cmH}_{2} \mathrm{O}$.

\subsection{Statistical analysis}

Variables were described using percentage, mean, standard deviation and quartiles. All series of measurements have been repeated three times in order to reduce the uncertainty using the formula: $\sqrt{ }\left(\mathrm{U}_{\text {reading }}{ }^{2}+\mathrm{U}_{\text {repetability }}{ }^{2}+\mathrm{U}_{\text {standard }}{ }^{2}\right)=0.7 \mathrm{cmH}_{2} \mathrm{O}$. The uncertainty of reading was related to the graduation of the pressure gauge. A " $\mathrm{B}$ " type of uncertainty was presented by the resolution of the pressure gauge graduation (gap of $2 \mathrm{cmH}_{2} \mathrm{O}$ ). This resolution was divided by six to obtain the uncertainty of reading $\left(\mathrm{U}_{\text {reading }}=0.33 \mathrm{cmH}_{2} \mathrm{O}\right)$. The expanded uncertainty of reading for a standard deviation of $95 \%(\mathrm{~K}=2)$ was $\mathrm{U}_{\text {reading }}=0.66 \mathrm{cmH}_{2} \mathrm{O}$. The pressure gauge uncertainty of repeatability was a "A" type of uncertainty. It was evaluated with the standard deviation from three different pressure gauges models. With 210 measurements, a Student's coefficient for ten measurements with a $95 \%$ confidence index $=2.23$ was applied. The repeatability was then assessed using the formula: $U_{\text {repeatability }}$ Student's * coefficient (mean standard deviation/measurement number $)=0.02899 \mathrm{cmH}_{2} \mathrm{O}$. Compared to uncertainty of the repeatability of the model, it is possible to estimate the validity of the series of measurements. $U_{\text {standard }}$ was defined by the quarter of the uncertainty precision of the pressure gauge calibrator, it was equal to $0.0176 \mathrm{cmH}_{2} \mathrm{O}$. A tolerance area of $2 \mathrm{cmH}_{2} \mathrm{O}$ was selected (excluding any risk of complications). It has been subtracted from the propagation of uncertainties i.e. $0.7 \mathrm{cmH}_{2} \mathrm{O}$, so a conformity zone of $1.3 \mathrm{cmH}_{2} \mathrm{O}$ (Fig. 1). The conformity of the manometer was validated if the leak test was negative and also if a difference between the displayed value of the calibrator and the pressure gauge was less than $1.3 \mathrm{cmH}_{2} \mathrm{O}$ in the range $20-30 \mathrm{cmH}_{2} \mathrm{O}$.

\section{Results}

The measurements were performed at the University Hospital of Nancy (France) with all cuff pressures that were usually used in the operating room. The mean (SD) temperature during the test were stable at $22.26{ }^{\circ} \mathrm{C}(1.68)$. The 


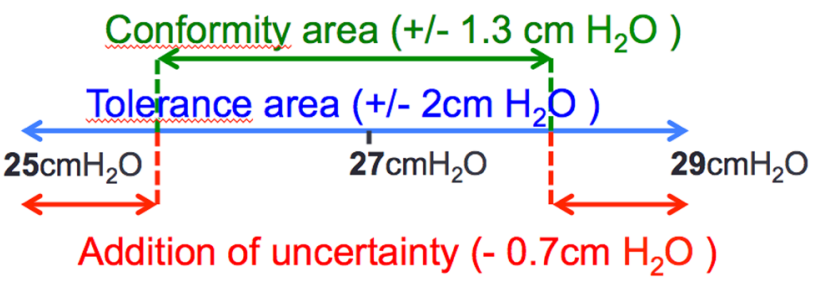

Fig. 1 Statistical analysis of the tolerance area: an addition of uncertainty of the conformity area

mean (SD) hygrometry during the tests were $25.96 \%$ (3.23). 27 cuff pressure gauges from three companies [Covidien (Dublin, Ireland) $n=7$, Mallinckrodt (Dublin, Ireland) $n=17$ and Portex (La Chapelle-Saint-Luc, France) $n=3$ ] were tested. All the cuff pressure gauges were from the university hospital. A total of 567 measurements were performed: one leak test for cuff pressure gauges and seven measurements at each defined level of pressure $(0,10,20,27,30,40$ and $50 \mathrm{cmH}_{2} \mathrm{O}$ ) repeated three times for each cuff pressure gauges. The real variations of the calibrator at different levels of pressure of the cuff pressure gauges are represent in the Table 1. The measurements of the real pressure of the calibrator at different levels of pressure are shown in on the Table 2 and the Fig. 2. The variation of pressure measured with the calibrator at different levels of pressure per company is represented in the Fig. 3.

Only $30 \%(n=8 / 27)$ of the cuff pressure gauges reached our homologation criteria. $30 \%(\mathrm{n}=8 / 27)$ failed at the leak test. $48 \%(n=13 / 27)$ of the cuff pressure gauges tested, had a calibration variation error $>1.3 \mathrm{cmH}_{2} \mathrm{O}$ on the levels of pressure of $20-30 \mathrm{cmH}_{2} \mathrm{O}$. The mean (SD) [min-max] of these non-homologation variations of the calibration on pressure levels were at $20 \mathrm{cmH}_{2} \mathrm{O}:+1.8(1)[0.1-4.1] \mathrm{cmH}_{2} \mathrm{O}$, at $27 \mathrm{cmH}_{2} \mathrm{O}:+1.8(1.2)[0.2-4.9]$ and at $30 \mathrm{cmH}_{2} \mathrm{O}:+1.8$ (1) [0.3-4] $\mathrm{cmH}_{2} \mathrm{O}$. Only $7 \%(\mathrm{n}=2 / 27)$ of cuff pressure gauges have failed both the homologation criteria.

At the optimal pressure to avoid complications $\left(27 \mathrm{cmH}_{2} \mathrm{O}\right), 11 \%(\mathrm{n}=3 / 27)$ of the cuff pressure gauges are

Table 1 Measurements of the real variations of the calibrator at different level of pressure of the cuff pressure gauges

\begin{tabular}{llllll}
\hline $\begin{array}{l}\text { Level } \\
\text { pressure } \\
\left(\mathrm{cmH}_{2} \mathrm{O}\right)\end{array}$ & $\mathrm{n}$ & $\begin{array}{l}\text { Mean } \\
\left(\mathrm{cmH}_{2} \mathrm{O}\right)\end{array}$ & $\begin{array}{l}\text { Standard } \\
\text { deviation } \\
\left(\mathrm{cmH}_{2} \mathrm{O}\right)\end{array}$ & $\begin{array}{l}\text { Minimum } \\
\left(\mathrm{cmH}_{2} \mathrm{O}\right)\end{array}$ & $\begin{array}{l}\text { Maximum } \\
\left(\mathrm{cmH}_{2} \mathrm{O}\right)\end{array}$ \\
\hline 0 & 27 & +0.69 & 1.12 & 0.00 & 4.81 \\
10 & 27 & +1.18 & 0.97 & 0.11 & 4.55 \\
20 & $27+1.15$ & 0.98 & 0.03 & 4.13 \\
27 & $27+1.08$ & 1.09 & 0.01 & 4.91 \\
30 & $27+1.24$ & 0.96 & 0.11 & 4.00 \\
40 & $27+1.21$ & 0.98 & 0.02 & 3.54 \\
50 & $27+1.42$ & 1.11 & 0.24 & 4.53 \\
\hline
\end{tabular}

Table 2 Measurements of the real pressure of the calibrator at different level of pressure

\begin{tabular}{llllll}
\hline $\begin{array}{l}\text { Level } \\
\text { pressure } \\
\left(\mathrm{cmH}_{2} \mathrm{O}\right)\end{array}$ & $\mathrm{n}$ & $\begin{array}{l}\text { Mean } \\
\left(\mathrm{cmH}_{2} \mathrm{O}\right)\end{array}$ & $\begin{array}{l}\text { Standard } \\
\text { deviation } \\
\left(\mathrm{cmH}_{2} \mathrm{O}\right)\end{array}$ & $\begin{array}{l}\text { Minimum } \\
\left(\mathrm{cmH}_{2} \mathrm{O}\right)\end{array}$ & $\begin{array}{l}\text { Maximum } \\
\left(\mathrm{cmH}_{2} \mathrm{O}\right)\end{array}$ \\
\hline 0 & 27 & +0.6 & 1.2 & -0.3 & +4.8 \\
10 & 27 & +10.7 & 1.4 & +7.9 & +14.5 \\
20 & 27 & +20.5 & 1.4 & +17.6 & +24.1 \\
27 & 27 & +27.6 & 1.4 & +25.1 & +31.9 \\
30 & 27 & +30.5 & 1.5 & +27.0 & +34.0 \\
40 & 27 & +40.4 & 1.5 & +37.3 & +43.5 \\
50 & 27 & +50.6 & 1.7 & +47.2 & +54.5 \\
\hline
\end{tabular}

potentially dangerous with an under estimation of the real pressure. The real mean pressure of these three cuff pressure gauges are not $27 \mathrm{cmH}_{2} \mathrm{O}$ but 29.4, 29.7 and $31.9 \mathrm{cmH}_{2} \mathrm{O}$ respectively.

There is an increase of the variations between the 10th and the 90th percentiles at high levels of pressure. The maximal difference of one measure was $+5.1 \mathrm{cmH}_{2} \mathrm{O}$ at a $50 \mathrm{cmH}_{2} \mathrm{O}$ level. The higher is the pressure, the wider is the imprecision.

\section{Discussion}

This study demonstrates that the majority of the cuff pressure gauges available on the market and tested in this study had a variation of the inflation pressure especially at the highest levels of pressure. For endotracheal recommended pressure, the difference is not clinically alarming.

In this study, some models of cuff pressure gauges could not be tested because they were not available in the hospital during the evaluation. The cuff pressure gauges tested were those used every day in the operating room of the single institution that conducted this evaluation. In France, it is not legally necessary to report on the longevity (number of years used in clinical practice) of those medical devices [9]. As a consequence, we did not know in our center for how long these devices had been in use. This may influence the outcome of the measurements. These devices required no mandatory follow-up by biomedical engineering. In France, medical devices are subjected to a classification in critical category according to Annex IX of European Directive/Regulation 93/42/EEC [9]. This classification is made according to 18 rules [9]. To date, cuff pressure gauges are classified in the first category and are not subjected to any monitoring or follow-up on their efficacy. This study shows that even if the results for clinical level of pressure are reassuring, the differences of the results between every cuff pressure gauges is probably a reason to change the classification in the critical category 
Fig. 2 Variation of cuff pressure gauges measured with the calibrator at different levels of pressure. Open boxes represent the 1st to 3rd quartiles and contain the median (horizontal bar) and the mean (blue diamond); vertical bars represent maximum between minimum and $\mathrm{Q} 1-1.5(\mathrm{Q} 3-\mathrm{Q} 1)$ and, minimum between maximum and $\mathrm{Q} 3+1.5(\mathrm{Q} 3-\mathrm{Q} 1)$ (where $\mathrm{Q} 1$ is the 1st quartile, Q3 the 3rd quartile)

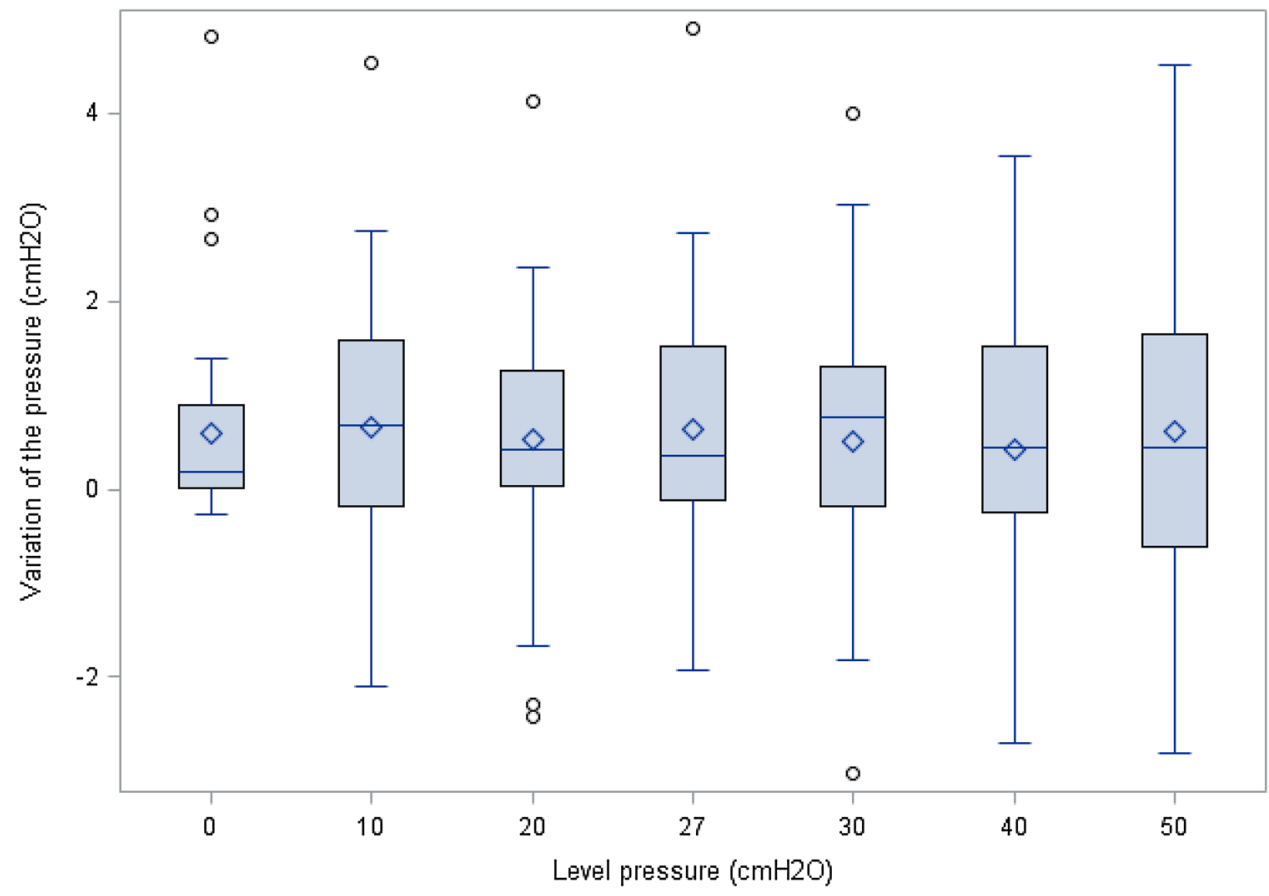

Fig. 3 Variation of cuff pressure gauges measured with the calibrator at different levels of pressure per company (Mallinckrodt $\mathrm{n}=17$, Covidien $\mathrm{n}=7$, Portex $n=3$ ). Open boxes represent the 1 st to 3 rd quartiles and contain the median (horizontal bar) and the mean (circle); vertical bars represent maximum between minimum and $\mathrm{Q} 1-1.5(\mathrm{Q} 3-\mathrm{Q} 1)$ and, minimum between maximum and $\mathrm{Q} 3+1.5(\mathrm{Q} 3-\mathrm{Q} 1)$ (where $\mathrm{Q} 1$ is the 1st quartile, Q3 the 3rd quartile)

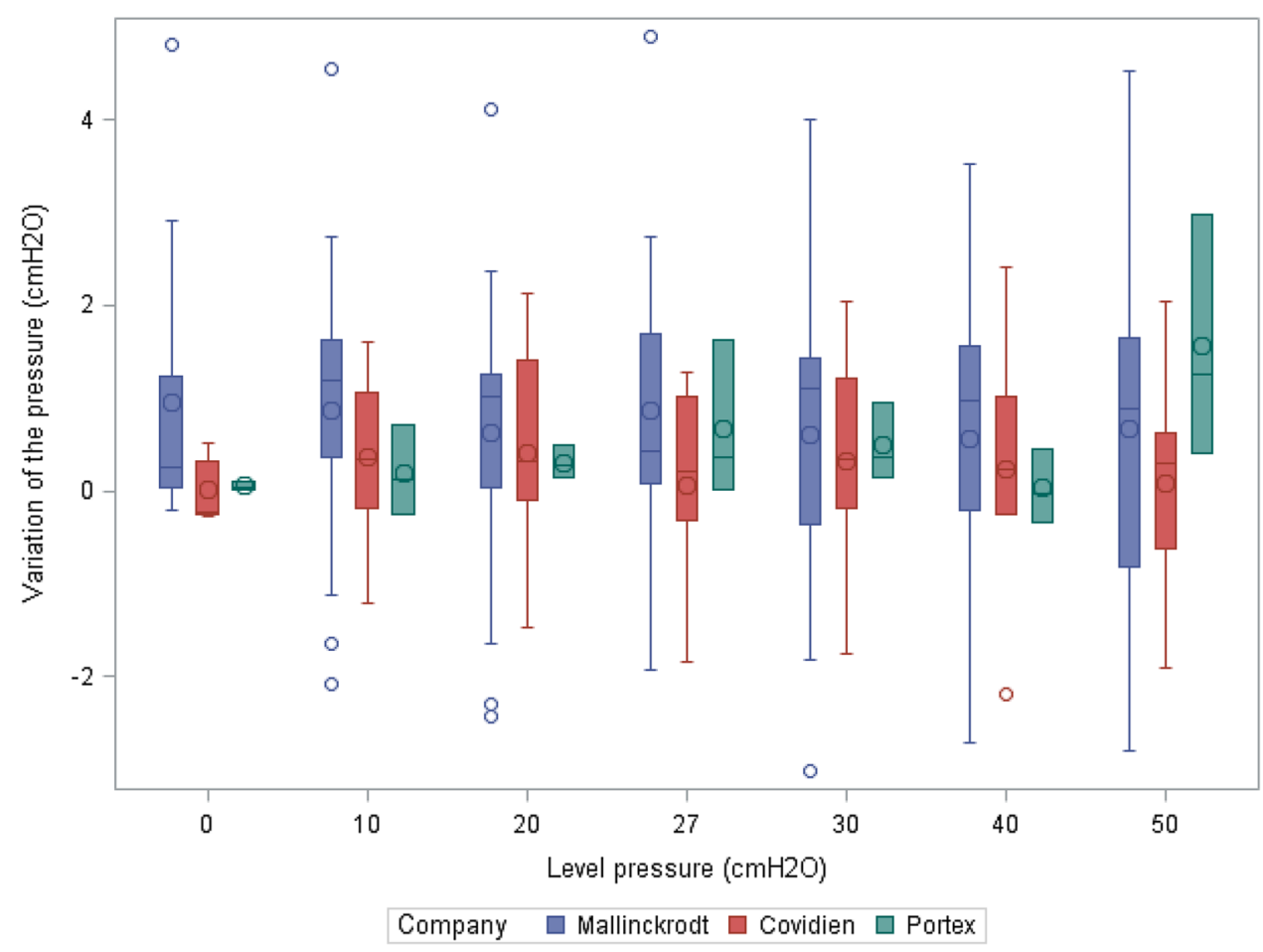

and then ensure regular monitoring by biomedical engineering to ensure reliability. This study suggests that future evaluations will necessarily have to integrate the control of the pressure of the cuff pressure gauges with a calibrator. Without this controls, it will be difficult to draw any conclusions from studies on factors inducing tracheal tissue ischemia.
Some cuff pressure gauges are not adapted to the use in anesthesia practice. In fact, they are arbitrarily provided by the manufacturers of an inflation pressure area, characterized by a wide, falsely reassuring area, sometimes ranging from 0 to $35 \mathrm{cmH}_{2} \mathrm{O}$ (Fig. 4). Inaccurate size of endotracheal tube cuff may lead to inadequate ventilation during anesthesia and tissue ischemia may occur above $30 \mathrm{cmH}_{2} \mathrm{O}$ [3-5]. 


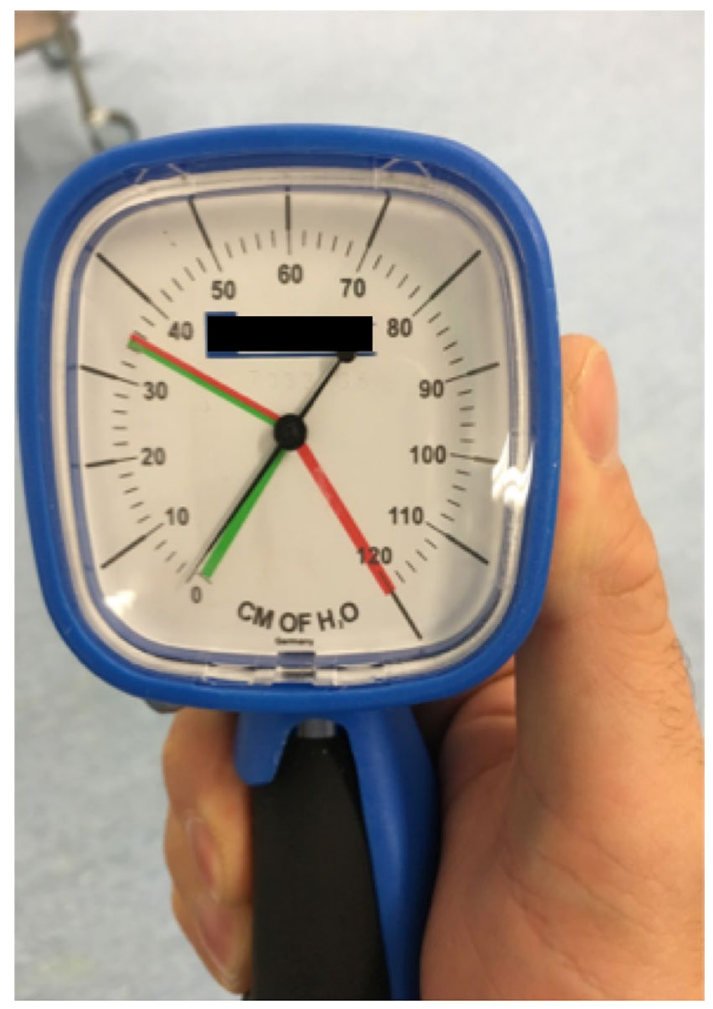

Fig. 4 Cuff pressure gauges with a wide ranging from 0 to $35 \mathrm{cmH}_{2} \mathrm{O}$

For this study, the optimal pressure chosen to avoid complications was fixed at $27 \mathrm{cmH}_{2} \mathrm{O}$ according to the French recommendations [8]. So, the drawing of this pressure area on future devices could be modified to be within a reduced range of $26-28 \mathrm{cmH}_{2} \mathrm{O}$. Especially because this study shows that imprecision is more present for high levels of pressure.

In clinical practice, the uncertainty of reading was related to the graduation of the pressure gauge. The resolution of the pressure gauge graduation seems to be to low (gap of $2 \mathrm{cmH}_{2} \mathrm{O}$ ). It's certainly necessary to focus on digital cuff pressure gauges to overpass this uncertainty.

In conclusion, a minority of cuff pressure gauges, used daily in the operating room, goes through our homologation criteria. These results demonstrate that there is a real problem of reliability and follow-up of those medical devices. An anesthesiologist must be able to trust the devices he uses daily. This study suggests to perform a regular and mandatory follow-up by biomedical engineering on our cuff pressure gauges devices. Further studies are necessary to check the frequency of the monitoring of cuff pressure gauges and the reliability according to their age and number of years in use.

Acknowledgements Mr Johan Labno nurse anesthetist, Mr Nicolas Lambert, nurse anesthetist, Mrs Caroline Lavaux, nurse anesthetist for their help at the recording data.

Author Contributions Study design: JR, A-SL, BM, IC-U, CB, HB. Recording data: A-SL, BM. Interpreting data: JR, A-SL, BM, IC-U, CB, PR, HB. Data analysis: JR, A-SL, BM, IC-U, CB, PR, HB. Writing manuscript: JR, A-SL, IC-U, CB, PR, HB. Reading manuscript: JR, A-SL, IC-U, CB, PR, HB.

\section{Compliance with ethical standards}

Conflict of interest Julien Raft, Anne-Sophie Lamotte, Bruno Maury, Isabelle Clerc-Urmès, Cédric Baumann, and Hervé Bouaziz declared no conflict of interest. Philippe Richebé: Honorarium as a consultant for the following companies: Medasense, Abbvie, Medtronic-Covidien, Biosyent, Merck. Member of the Scientific Advisory board of Medasense LTD since 2014.

\section{References}

1. Efrati S, Deutsch I, Gurman GM. Endotracheal tube cuffsmall important part of a big issue. J Clin Monit Comput. 2012;26:53-60.

2. Seegobin RD, Van Hasselt GL. Endotracheal cuff pressure and tracheal mucosal blood flow: endoscopic study of effects of four large volume cuffs. Br Med J. 1984;288:965-8.

3. Dobrin P, Canfield T. Cuffed endotracheal tubes: mucosal pressures and tracheal wall blood flow. Am J Surg. 1977;133:562-8.

4. Nordin U, Lindholm CE, Wolgast M. Blood flow in the rabbit tracheal mucosa under normal conditions and under the influence of tracheal intubation. Acta Anaesthesiol Scand. 1977;21:81-94.

5. Rokamp K, Secher N, Møller A, Nielson H. Tracheal tube and laryngeal mask cuff pressure during anaesthesia-mandatory monitoring is in need. BMC Anesthesiol. 2000. https://doi. org/10.1186/1471-2253-10-20.

6. Combes X, Schauvliege F, Peyrouset O, Motamed C, Kirov K, Dhonneur G, Duvaldestin P. Intracuff pressure and tracheal morbidity: influence of filling with saline during nitrous oxide anesthesia. Anesthesiology. 2001;95:1120-4.

7. Décret sécurité - 8/12/1994 - Société Française d'Anesthésie et réanimation - Sfar. http://sfar.org/decret-securite-8121994/. Accessed 16 Mar 2018.

8. Prise en charge des voies aériennes en anesthésie adulte à l'exception de l'intubation difficile - Sfar. http://sfar.org/prise -en-charge-des-voies-aeriennes-en-anesthesie-adulte-a-lexception -de-lintubation-difficile/. Accessed 16 Mar 2018.

9. Texte de la directive dispositifs médicaux 93/42/CE - LNE. http:// www.Ine.fr/publications/directives/93-42.pdf. Accessed 31 Mar 2018. 